\title{
Restorative proctocolectomy and pouch anal anastomosis for ulcerative colitis following orthotopic liver transplantation
}

\author{
S Rowley, D Candinas, A D Mayer, J A C Buckels, P McMaster, M R B Keighley
}

\begin{abstract}
This study reports on the outcome of four patients having ileal pouch anal anastomosis after orthotopic liver transplantation for sclerosing cholangitis complicating ulcerative colitis. There were no deaths on follow up. Early postoperative bleeding was a complication of colectomy or rectal excision in three, one of whom developed hepatic artery thrombosis and the overall complication rate was high. All patients are continent but one has chronic pouchitis (while receiving longterm metronidazole) and one patient has recurrent sclerosing cholangitis in the transplant.

(Gut 1995; 37: 845-847)
\end{abstract}

Keywords: proctocolectomy, pouch anal anastomosis, ulcerative colitis, liver transplantation.

There is a known association between sclerosing cholangitis and ulcerative colitis, ${ }^{12}$ thus some patients undergoing orthotopic liver transplantation have already had surgery for ulcerative colitis. ${ }^{3}$ There are no reports of patients who have had liver transplants requiring subsequent surgery for ulcerative colitis. We report four such patients and highlight some of the problems that may be encountered.

\section{Case 1}

A man was diagnosed as having total ulcerative colitis at 19 years (1970). In 1982 he became jaundiced with clubbing and splenomegaly. Liver biopsies showed established cirrhosis and features of cholestasis. Cholangiography confirmed sclerosing cholangitis. He developed portal hypertension, liver function deteriorated, and he underwent an uncomplicated liver transplant with Roux biliary reconstruction at 39 years (1990). He was initially given immunosuppressants prednisolone, cyclosporin $\mathrm{A}$, and azathioprine. Later this was reduced to cyclosporin A alone. Postoperatively he continued to have diarrhoea and recurrent acute colitis with mild dysplasia. He underwent colectomy and subsequently an ileopouch anal anastomosis (1992). The covering loop ileostomy was closed three months later. Subsequently, he has had repeated episodes of pouchitis requiring anti-diarrhoeal agents and metronidazole. He is currently continent, opening his bowels six to eight times a day but requires continuous metronidazole to maintain a manageable bowel frequency. His liver function tests have remained normal.

\section{Case 2}

A 6 year old girl developed total ulcerative colitis with persistent diarrhoea in 1980 despite corticosteroids (her father has ulcerative colitis treated by ileopouch anal anastomosis in 1990). She developed features of sclerosing cholangitis during 1986 and underwent orthotopic liver transplantation in May 1987 because of deteriorating liver function. At transplantation she was found to have a thrombosed portal vein and portal hypertension. A Roux biliary reconstruction was used and she was given prednisolone, azathioprine, and cyclosporin A. She continued to have active colitis and underwent colectomy two years after transplantation (1991), complicated by intra-abdominal haemorrhage requiring early re-laparotomy and clot evacuation. She later underwent ileopouch anal anastomosis (1992) with a covering ileostomy, which was closed in January 1993. Her liver function tests have subsequently deteriorated and biopsy of the transplant shows recurrent sclerosing cholangitis. Subsequently, she developed chronic small bowel obstruction with folate and iron deficiency anaemia, necessitating a laparotomy, which showed mechanical obstruction and an enteroenteric fistula. She was treated by closure of the defect and release of the obstruction. She continues to be treated with a rotating course of augmentin, trimethaprin, and ciprofloxacin for recurrent episodes of cholangitis.

\section{Case 3}

A 21 year old man presented in 1986 with weight loss, jaundice, and bloody diarrhoea. Total ulcerative colitis was treated with corticosteroids, mesalazine, azathioprine but shortly afterwards he developed sclerosing cholangitis. He required an orthotopic liver transplantation with Roux biliary reconstruction (1991) because of progressive liver failure. He was treated with cyclosporin A, prednisolone, and azathioprine. Severe diarrhoea persisted after transplantation and colonic biopsies showed total colitis with dysplasia and cytomegalovirus inclusion bodies. $\mathrm{He}$ underwent an urgent colectomy (1993) complicated by profuse intra-abdominal bleeding requiring eight units of blood, which settled without re-operation. Two days later Doppler ultrasound showed a thrombosed hepatic artery associated with transient derangement of liver function tests. An elective uneventful ileopouch anal anastomosis with a covering ileostomy was performed in January 
1994 and he is currently well 12 months after ileostomy closure with a bowel frequency of four stools in 24 hours.

\section{Case 4}

A 19 year old man presented with total ulcerative colitis and abnormal liver function tests with established sclerosing cholangitis on liver biopsies in 1971 . The colitis dominated the picture and he underwent colectomy in 1987 with the intention of including a synchronous ileopouch anal anastomosis but this was considered too hazardous in the face of portal hypertension. He subsequently developed bleeding oesophageal varices (1990) and deteriorating liver function requiring orthotopic liver transplantation (1991) and Roux biliary reconstruction. Postoperative immunosuppression was initially with prednisolone, azathioprine, and cyclosporin A but was subsequently maintained with cyclosporin A alone. Continued bloody discharge from the rectal stump led to rectal excision and ileopouch anal anastomosis (1993) with covering ileostomy but this was complicated by pelvic haematoma, which was drained percutaneously under ultrasound control. The loop ileostomy was closed in January 1994, liver function tests remain normal, and he is continent with a bowel frequency of five to seven stools per 24 hours.

The Table shows the results of ileopouch anal anastomosis after orthotopic liver transplantation.

\begin{abstract}
Discussion
Definitive surgery for ulcerative colitis in the presence of sclerosing cholangitis has been reported previously in patients without orthotopic liver transplantation but this is the first report of patients treated by ileopouch anal anastomosis for underlying ulcerative colitis after liver transplantation. Post-transplant colectomy is an uncommon scenario as the colonic disease, if it needs treatment at all, is usually resected before the liver disease. Sclerosing cholangitis is now the third most common cause for liver transplantation both in our series and in others. ${ }^{1}$ Sixty two transplants have been performed for sclerosing cholangitis in the first 754 patients in our programme, five of these patients had required colectomy before transplantation and the four reported here underwent definitive surgical treatment afterwards. It is envisaged that surgery for ulcerative colitis in patients after orthotopic liver transplantation will become more common with longer post-transplant survival
\end{abstract}

Results of ileopouch anal anastomosis after orthotopic liver transplantation

\begin{tabular}{|c|c|c|c|c|c|}
\hline Patient & $\begin{array}{l}\text { Time } \\
\text { after OLT } \\
\text { (months) }\end{array}$ & $\begin{array}{l}\text { Current liver } \\
\text { function } \\
\text { tests }\end{array}$ & $\begin{array}{l}\text { Current } \\
\text { clotting }\end{array}$ & Early complications & Late complications \\
\hline 1 & 28 & Normal & $13 / 12$ & None & Chronic pouchitis \\
\hline 2 & 26 & Raised AP & $15 / 15$ & Bleeding & $\begin{array}{l}\text { Cholangitis/chronic rejection. } \\
\text { Obstruction/fistula }\end{array}$ \\
\hline 3 & 14 & Normal & $15 / 15$ & $\begin{array}{l}\text { Bleeding. Hepatic } \\
\text { artery thrombosis }\end{array}$ & None \\
\hline 4 & 30 & Normal & $13 / 12$ & Pelvic haemorrhage & None \\
\hline
\end{tabular}

$\mathrm{AP}=$ alkaline phosphatase both for symptomatic relapse and for cancer prophylaxis in the immunosuppressed patients.

Since the introduction of ileopouch anal anastomosis ${ }^{4}$ this surgical option has been gaining increasing acceptance and is now considered by many to be the treatment of choice for young, well motivated patients undergoing colectomy for ulcerative colitis. More than $90 \%$ of patients can expect an almost normal quality of life after ileopouch anal anastomosis, ${ }^{5}$ whereas frequent problems can be expected after colectomy and Brooke ileostomy with a re-intervention rate of $67 \%{ }^{6}$

In our previous report of non-transplanted patients, postoperative haemorrhage was found to be uncommon after ileopouch anal anastomosis, being recorded in only four of 168 cases. ${ }^{7}$ Bleeding is a recognised problem, however, in patients having definitive surgery for ulcerative colitis in the presence of sclerosing cholangitis without transplantation. ${ }^{3}$ Furthermore, this experience shows that bleeding was encountered in three of four cases, thus definitive surgery in the post-transplant patient calls for special vigilance.

All four patients had a Roux biliary reconstruction to avoid using a diseased native bile duct. This is a theoretical disadvantage in that during formation of the $J$ pouch there may be insufficient length in the small bowel mesentry to achieve a tension free anastomosis but we did not find this to be a problem. Furthermore, it was possible to construct a covering loop ileostomy to protect the anastomosis and minimise the consequences of pelvic sepsis in these immunosuppressed patients because we know that pelvic sepsis may compromise pouch function. ${ }^{8}$

Pouchitis, which is reported in between $5-40 \%$ of non-transplanted patients, ${ }^{9}$ occurred in one of our four immunosuppressed patients. If pouchitis were to prove common it might theoretically provide the immunological and microbiological stimulus to the development of sclerosing cholangitis and strictures in the transplant.

In none of these cases did the complications of colonic surgery irretrievably damage the transplanted liver, although there was considerable concern in two cases (case 2 and 3). In one, ileal stasis with bacterial overgrowth and folate deficiency, which persists despite correction of an enteroenteric fistula, may contribute to an accelerated recurrence of sclerosing cholangitis in the graft. In the other, hepatic artery thrombosis occurred after colectomy. Despite this, liver function remains normal but the longterm outlook is uncertain.

We believe that definitive colorectal surgery, and even pouch operations, are feasible and may be advised in selected cases for symptomatic ulcerative colitis after orthotopic liver transplantation. We would draw attention to a higher complication rate, however, and the possible risks to the transplanted liver, especially if there is small bowel stasis and bacterial overgrowth. Clearly, close cooperation between the coloproctologists and the transplant team is essential. 
ADDENDUM-Since submitting this paper case 2 has died of progressive liver failure from recurrent cholangitis. Retransplantation was considered but declined by the family.

1 Wiesner RH, Grabsch PM, Dickson ER, Ludwig J MacCarty RL, Hunter EB, et al. Primary sclerosing
cholangitis: natural history, prognostic factors and survival cholangitis: natural history, prognostic
analysis. Hepatology 1989; 10: 430-6.

2 Wiesner RH, LaRusso NF, Dozois RR, Beaver SJ. Peristomal varices after proctocolectomy in patients with primary sclerosing cholangitis. Gastroenterology 1986; 90: 316-22.

3 Kartheuser XH, Dozois RR, Wiesner RH, LaRusso NF, Ilstrup DM, Schleck CD. Complications and risk factors after ileal pouch-anal anastomosis colitis associated with primary sclerosing cholangitis. Ann Surg 1993; 217: 314-20.
4 Parks AG, Nicholls RJ. Proctocolectomy without ileostomy for ulcerative colitis. $B M \mathcal{F}$ 1978; 2: 85-8.

5 Kohler LW, Pemberton JH, Hodge DO, Zinsmeister AR Kelly A. Long term functional results of quality of life after ileal pouchanal anastomosis and cholecystectomy. World $\mathcal{f}$ Surg 1992; 16: 1126-32.

6 Leijonmarck C-E, Liljeqvist L, Poppen B, Hellers G. Surgery after colectomy for ulcerative colitis. Dis Colon Rectum 1992; 35: 495-502.

7 Keighley MRB, Grobler S, Bain I. An audit of restorative proctocolectomy. Gut 1993; 34: 680-4.

8 Buhr HJ, Heuschen UA, Stern J, Herfarth Ch Kontinenzerhaltende Operation nach Proktokolektomie. Chirurg 1993; 64: 601-13.

9 Braun J, Schumpelick V. Die Direkte Ileumpouchanlage Anastomose. Chirurg 1993; 64: 614-21. 